\title{
Effect of Alumina-Graphite Filler Blending on Tensile Behavior of Glass Fiber Reinforced Epoxy Composites
}

\author{
Puneeth Subramanian ${ }^{1 *}$, Tridib Das ${ }^{1}$, Chidambaram $G^{1}$ and Haseebuddin M.R ${ }^{2}$ \\ 1. UG Scholar, Department of Mechanical Engineering, DSCE, 560078, Bangalore \\ 2. Lecturer, Department of Mechanical Engineering, DSCE, 560078, Bangalore
}

\begin{abstract}
In this study, the effect of addition of alumina-graphite fillers on tensile properties of glass fabric reinforced epoxy resin composites has been evaluated experimentally. glass fiber/epoxy composites without filler and with $2 \%$, $4 \%$, and $6 \%$ filler content are fabricated using "Hand Lay Up” method. Each of the fabricated composite panel has equal percentage of alumina and graphite fillers by weight. Specimens from the fabricated plates are cut and testing is carried out in accordance with ASTM D-638. The properties like tensile strength, tensile modulus, elongation at break and deflection are studied. Modes of fracture and fiber-matrix adhesion are also studied. Results revealed that composites with increase in filler content show a decrease in tensile strength, whereas lower elongation, and decrease in tensile modulus compared to composites without filler. Effect of incorporation of alumina-graphite fillers, does not show much improvement in the fiber-matrix interface in the composite. Elongation properties decreased with the presence of filler that indicates interference by the filler in the mobility or deformability of the matrix. This interference was created through the physical interaction and immobilization of the polymer matrix due to the filler particles imposing mechanical constraints. The tests showed brittle fracture of the tested samples.
\end{abstract}

Key words: Alumina, graphite, glass fiber reinforced epoxy, “Hand Lay Up” method.

\section{Introduction}

Polymers and their composites have generated wide interest in various engineering fields. Glass fiber reinforced polymer composites are being increasingly used because of their low weight, manufacturing flexibility [1], low density, and anti-corrosion properties in automobile, aeronautical and marine applications. According to some studies polymer composites reduces component weight up to $50 \%$ if aluminum is replaced by polymer composites. Also various fillers are been used to enhance their properties [2, 3]. They are dimensionally stable material, which do not shrink at high temperatures which makes it a superior application material [4].

Epoxy or polyepoxide is a thermosetting polymer formed from reaction of an epoxide "resin" with polyamine "hardener". The resin consists of monomers or short chain polymers with an epoxide group at either

Corresponding author: Puneeth Subramanian. E-mail: puneethms@gmail.com. end. The hardener consists of polyamine monomers. When these compounds are mixed together, the amine groups react with the epoxide groups to form a covalent bond. Each NH group can react with an epoxide group, so that the resulting polymer is heavily cross linked, and is thus rigid and strong. The applications for epoxy based materials are extensive and include coatings, adhesives and composite materials such as those using carbon fiber and fiberglass reinforcements. The chemistry of epoxies and the range of commercially available variations allows cure polymers to be produced with a very broad range of properties. In general, epoxies are known for their excellent adhesion, chemical and heat resistance, good to excellent mechanical properties and very good electrical insulating properties, but almost any property can be modified (for example silver-filled epoxies with good electrical conductivity are available, although epoxies are typically electrically insulating) $[5,6]$.

Aluminium oxide is the family of inorganic 
compounds with the chemical formula $\mathrm{Al}_{2} \mathrm{O}_{3}$. It is an amphoteric oxide and is commonly referred to as alumina, corundum as well as many other names, reflecting its widespread occurrence in nature and industry. Its most significant use is in the production of aluminium metal, although it is also used as an abrasive due to its hardness and as a refractory material due to its high melting point. It is cost effective and has excellent dielectric properties, good thermal conductivity [7]. It also resists strong alkali and acid attacks at elevated temperatures and also available in purity ranges from $94 \%$ to $99.5 \%$.

Graphite is an allotrope of the chemical element carbon and is denoted by the symbol ' $\mathrm{C}$ '. Natural graphite occurs in three distinct forms in nature, crystalline graphite, amorphous graphite and lump graphite. It is very soft and has a greasy texture. It can be broken easily and leaves a black streak on the hand when touched. Although graphite is soft and flexible, it is not elastic in nature. It is inert to almost all chemicals and hence insoluble in water and other organic solvents.

Graphite has a sheet like structure where the atoms all lie in a plane and are only weakly bonded to the graphite sheets above and below. carbon atoms are in flat sheets and within the sheet, they are arranged in hexagons. Each carbon atom in graphite is directly linked to only three carbon atoms through covalent bonds. Therefore, of the four valence electrons in a

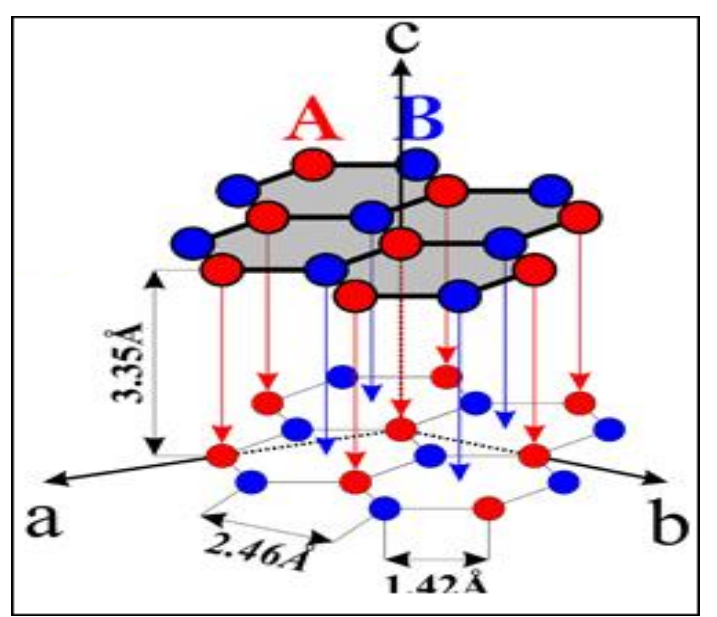

Fig. 1 Crystal lattice of graphite. carbon atom only three are used for bonding and the fourth is relatively free and can move from one atom to the other. The layers are held by comparatively weak forces. As a result, the layers are separated by large distances and can easily slide over the other. The distance between the layers is more than double the distance between the carbon atoms. This explains the lower density of graphite and also the slippery nature of graphite.

Glass fiber fabric reinforcement is dimensionally stable material which do not shrinks or stretch at high temperature and possess qualities like flexibility, high strength, low weight which makes it superior application properties. The most important factor for design with composites is the fiber/filler content, as it controls the mechanical properties. In order to obtain the desired material properties for a particular application, it is important to know the material performance changes with the filler content under given loading conditions. The tensile properties as a function of filler content has been studied to a limited extent in accordance with ASTM D-638.

In this study, glass fiber reinforced epoxy composites with varying percentages of alumina-graphite filler are fabricated. Samples are subjected to tensile tests for evaluating the strength properties of composite materials. The properties, including tensile strength, tensile modulus, stress at break, work at break and stress at maximum load are investigated in accordance with ASTM standards.

\section{Experiments}

\subsection{Materials}

Composites plates are prepared using glass fiber fabric $\left(200 \mathrm{~g} / \mathrm{m}^{3}\right)$ as reinforcement and epoxy resin is used as matrix material. Araldite HY 951 is used as hardener. A mixture of graphite and alumina is used as filler material.

\subsection{Sample Preparation}

Fabrication is done by "Hand Lay Up” method and 
composites are cured at room temperature. Epoxy resin is well stirred with 10\% hardener (Araldite HY 951). Then glass fabric is placed on the polyester matrix layer. Alternative layers of matrix and glass fabric are placed and rolled using a roller to remove any tapped air. 13 layers of glass fiber fabric were used to get the required thickness of $2.5 \mathrm{~mm}$, which was maintained by using stoppers of $2.5 \mathrm{~mm}$ thickness. The procedure was repeated to fabricate 3 more plates with the addition of mixture of alumina and graphite as filler material in steps of $2 \%, 4 \%$ and $6 \%$ respectively. Specimens were cut in accordance with ASTM D-638.

Details of compositions of composites fabricated are given in the table below.

\subsection{Tensile Strength Measurement}

Tensile tests were carried out on a JJ Lloyd
Universal Testing machine. The standard specimens are cut from the fabricated composite plates in accordance with ASTM D-638. A minimum of 10 specimens are tested in each case to obtain average values for tensile strength, modulus, stress at break, work at break and stress at maximum load.

\section{Results and Discussion}

\subsection{Elongation}

The results of elongation as a function of filler content of neat epoxy and their composites are shown in Fig. 3. For all the composites tested, it is observed that the elongation decreases linearly with increase in filler content.

At all filler content the highest elongation is for neat epoxy with a value of $4.9 \mathrm{~mm}$ and the lowest value of $3.64 \mathrm{~mm}$ for $6 \%$ filler content epoxy composite.

Table 1 Details of composition of composites.

\begin{tabular}{lllll}
\hline \multirow{2}{*}{ Samples } & Matrix (Wt.\%) & Reinforcement (Wt.\%) & \multicolumn{2}{c}{ Fillers (Wt.\%) } \\
\cline { 4 - 5 } & & 40 & Alumina & Graphite \\
\hline Epoxy-Glass Fiber & 60 & 38 & 0 & 0 \\
Epoxy-Glass Fiber-Filler & 60 & 36 & 1 & 2 \\
Epoxy-Glass Fiber-Filler & 60 & 34 & 3 & 3 \\
Epoxy-Glass Fiber-Filler & 60 & & 3 & 2 \\
\hline
\end{tabular}

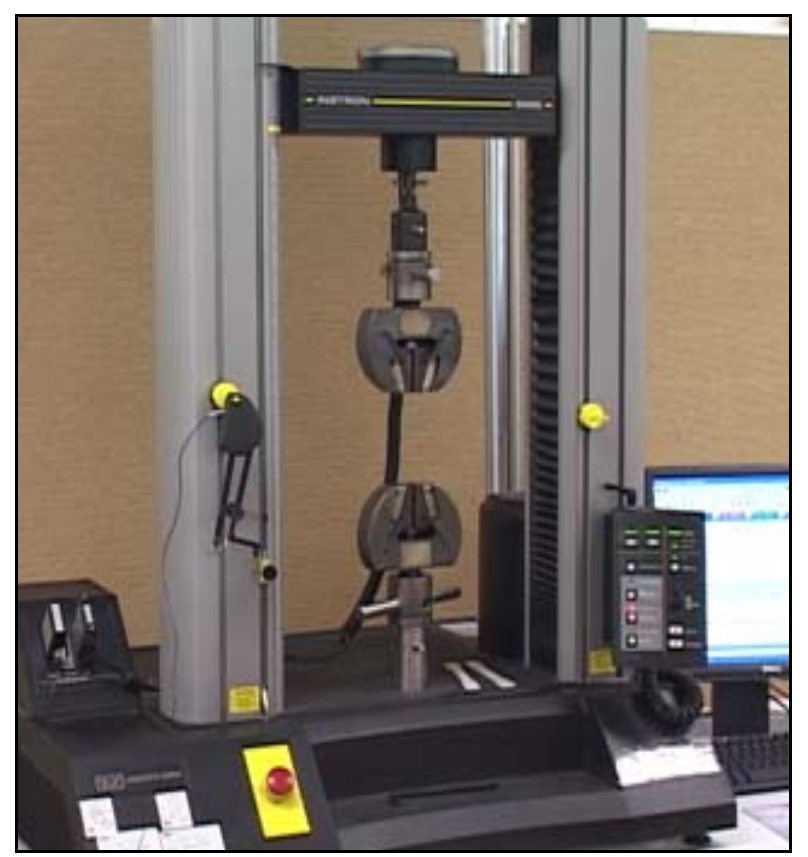

Fig. 2 JJ Lloyd universal testing machine. 

Fiber Reinforced Epoxy Composites

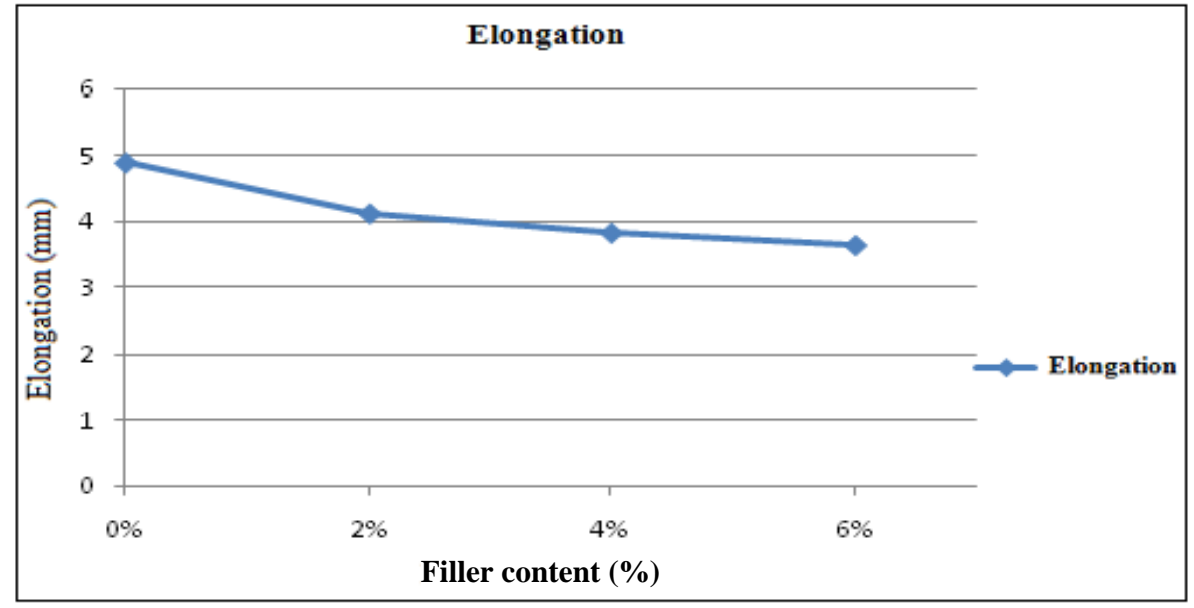

Fig. 3 Elongation v/s filer content $\%$.

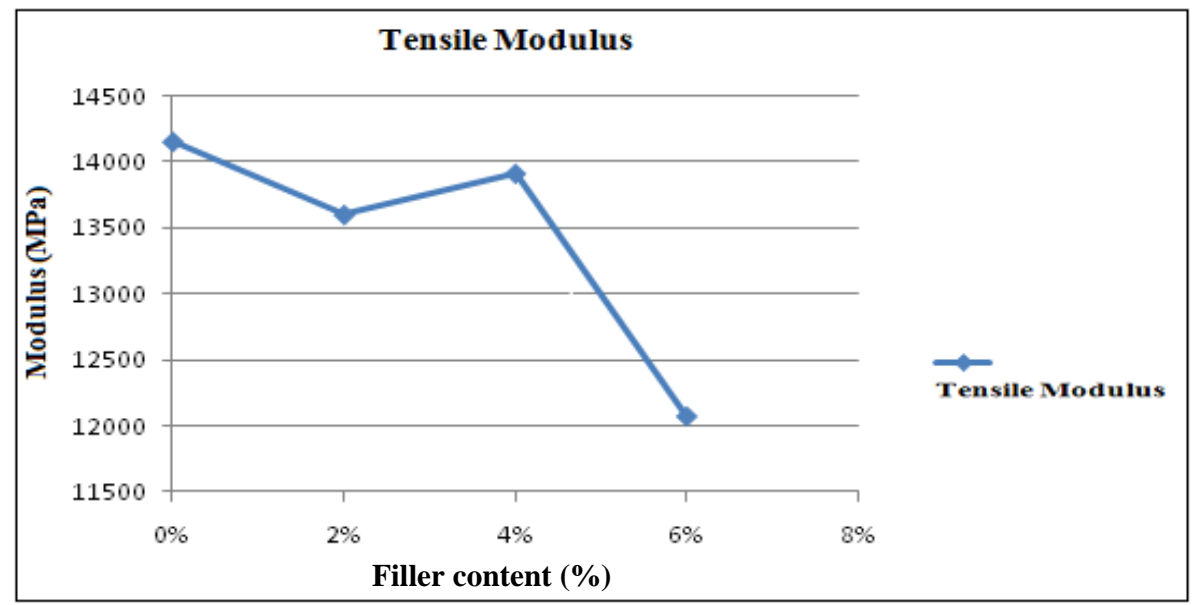

Fig. 4 Tensile modulus v/s filler content $\%$.

\subsection{Tensile Modulus}

The results of Tensile Modulus as a function of Filler Content of neat epoxy and their composites are shown in Fig. 4. For all the composites tested, it is observed that the tensile modulus decrease with increase in filler content.

At all filler content the highest tensile modulus is for neat epoxy with a value of $14,156.3 \mathrm{MPa}$ and the lowest value of 12,068.2 MPa for 6\% filler content epoxy composite.

\subsection{Stress at Break}

The results of Stress at Break as a function of Filler Content of neat epoxy and their composites are shown in Fig. 5. For all the composites tested, it is observed that the stress at break decreases linearly with increase in filler content.

At all filler content the highest stress at break is for neat epoxy with a value of $28.95 \mathrm{MPa}$ and the lowest value of $18.91 \mathrm{MPa}$ for $6 \%$ filler content epoxy composite.

\subsection{Work at Break}

The results of Work at Break as a function of Filler Content of neat epoxy and their composites are shown in Fig. 6. For all the composites tested, it is observed that the work at break decreases linearly with increase in filler content.

At all filler content the highest work at break is for neat epoxy with a value of $20.95 \mathrm{~J}$ and the lowest value of $13.6 \mathrm{~J}$ for $6 \%$ filler content epoxy composite. 


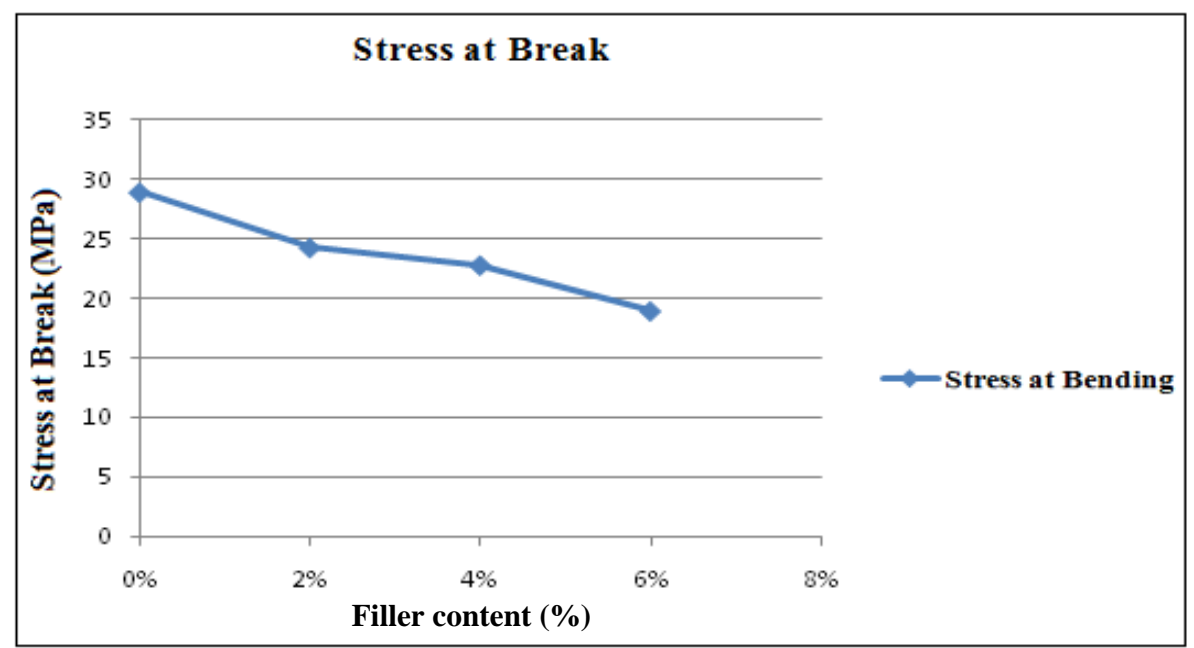

Fig. 5 Stress at break v/s filler content $\%$.

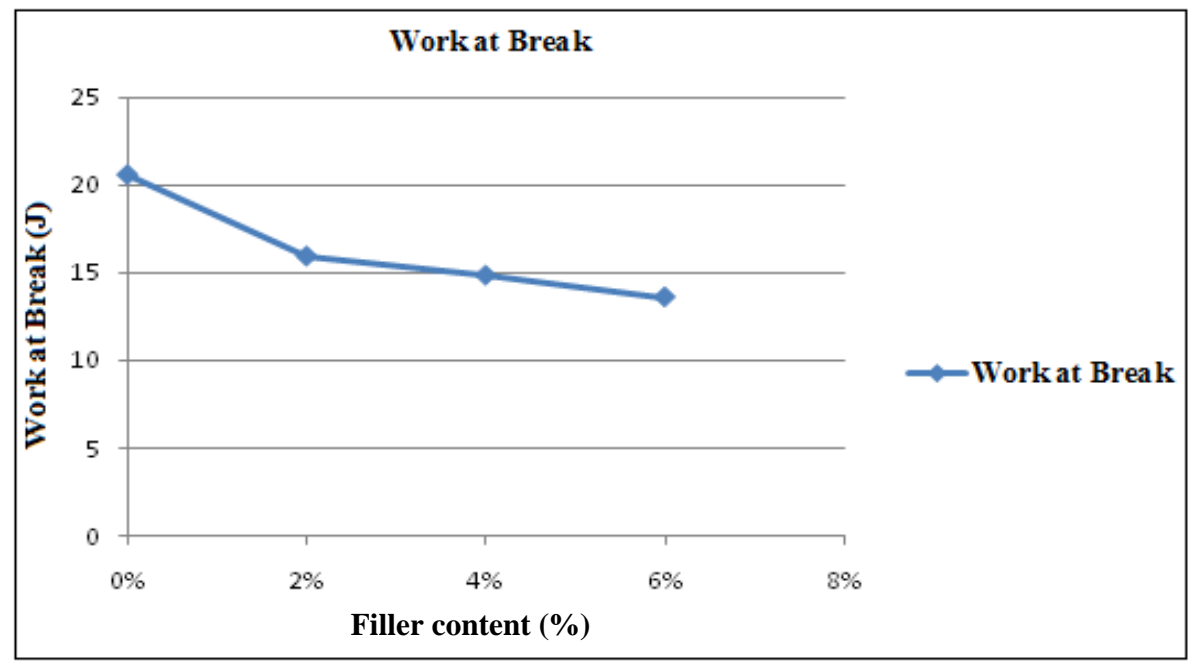

Fig. 6 Work at break v/s filler content \%.

\subsection{Stress at Maximum Load}

The results of Stress at maximum load as a function of Filler Content of neat epoxy and their composites are shown in Fig. 7. For all the composites tested, it is observed that the stress at max load decreases linearly with increase in filler content.

At all filler content the highest stress at maximum load is for neat epoxy with a value of 289.3 MPa and the lowest value of $189.8 \mathrm{MPa}$ for $6 \%$ filler content epoxy composite.

This is attributed to the fact that Al-Gr filled epoxy composite, the $0 \%$ filler content shows better results compared to the other filler contents $2 \%, 4 \%$ and $6 \%$.
Whereas, filler composites show deterioration with increase in the filler content.

\section{Fracture Analysis}

From photographs it is evident that test samples have experienced all basic modes of fracture encountered in case of glass fiber reinforced composites namely debonding, delamination and fiber pull out. Fig. 8(c) shows delamination of $2 \%$ filler composites and in Fig. 8(d) fiber pull out is observed. As seen (Fig. 8(a)) 2\% filler filled GF/epoxy composite the extend of debonding is limited by use of filler as filler particles have improved interfacial adhesion. This is proved by the fact that the fibers are fairly well covered by 

Fiber Reinforced Epoxy Composites

resin-filler mixture $2 \%$ filler filled GF/epoxy composites show better tensile properties compared to composites with $4 \%$ and $6 \%$ filler composites as proper bonding has occurred.

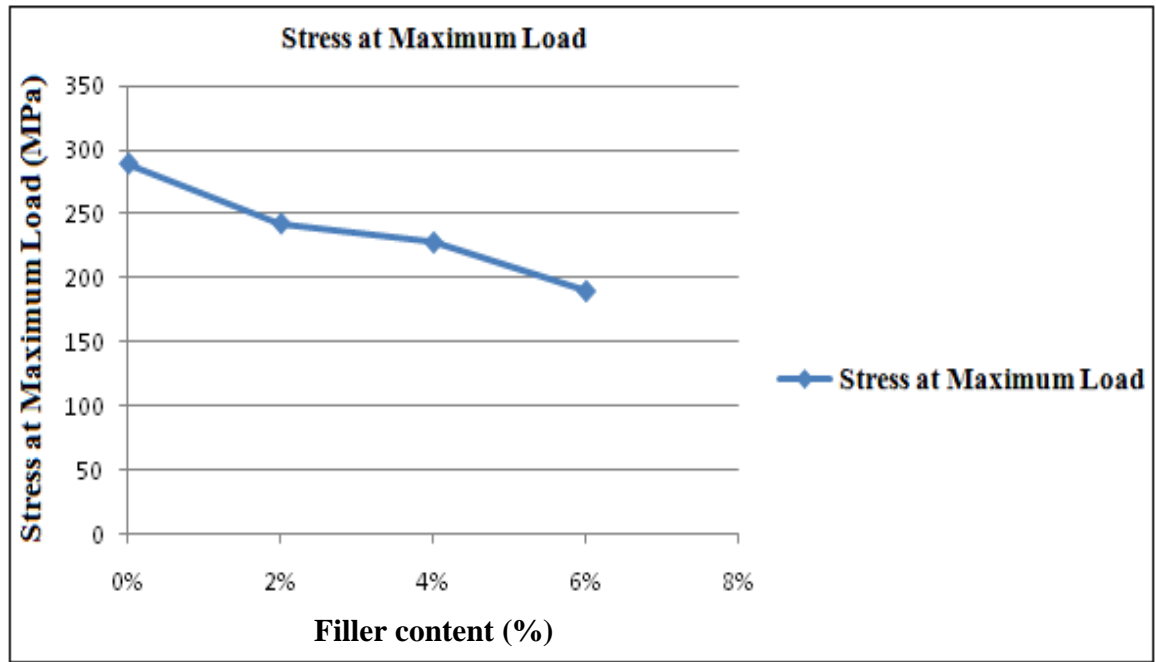

Fig. 7 Stress at maximum load v/s filler content $\%$.

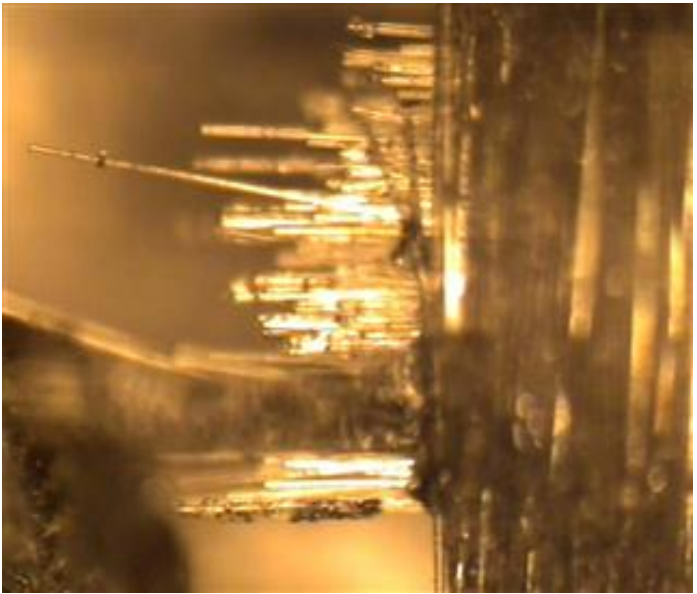

(a) Specimen with $2 \%$ filler

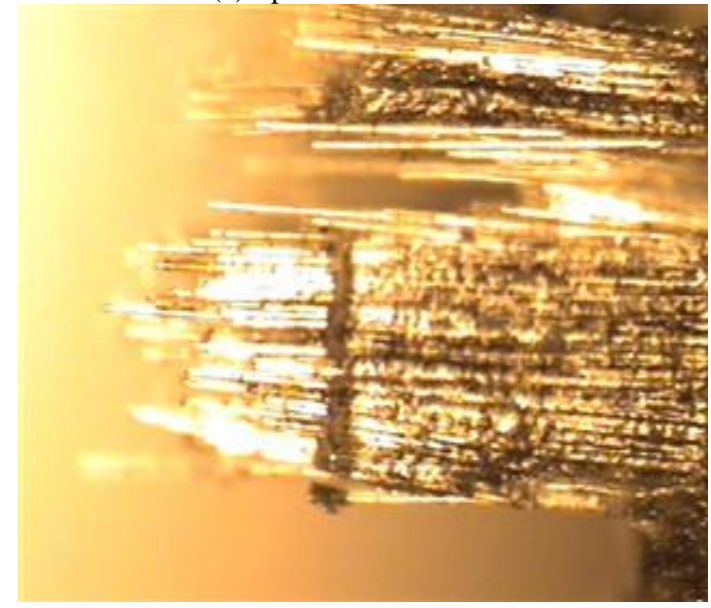

(c) Specimen with $2 \%$ filler-tip

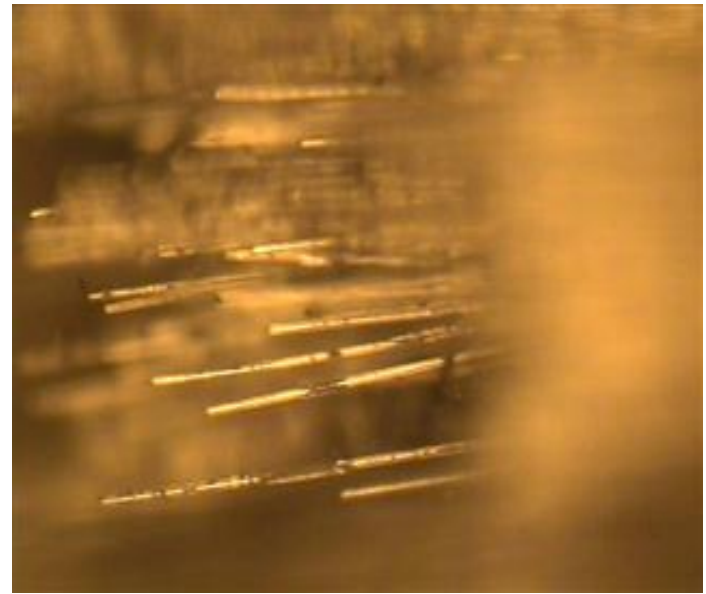

(b) Specimen with $4 \%$ filler

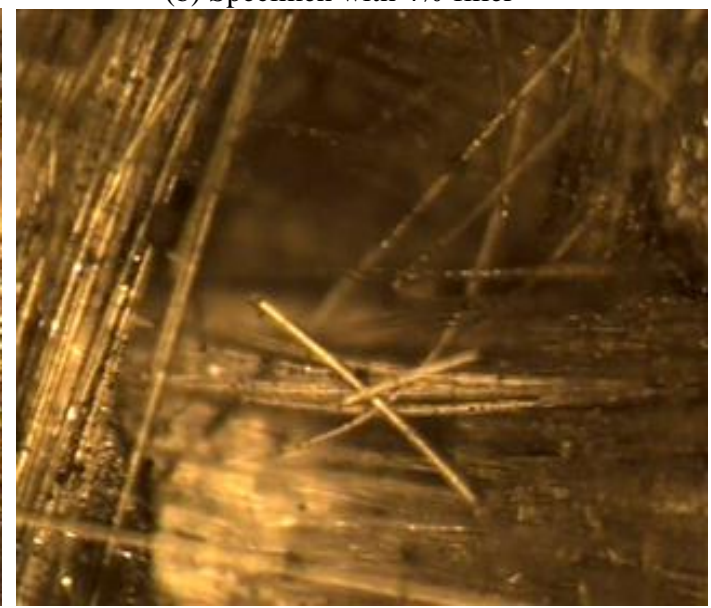

(d) Specimen with 6\% filler

Fig. 8 Photographs of specimen with different content of filler. 


\section{Conclusions}

Lot of work has been carried by researcher's using single filler and not much work is carried out using blending of two fillers. From this study the on effect of addition of alumina-graphite fillers on Tensile properties of glass fabric reinforced epoxy resin composites the following things are observed.

The elongation of glass fiber composites is decreasing with increase in Al-Gr filler content.

The tensile modulus also decreases with increase in filler content but samples with $4 \%$ filler content show higher tensile modulus compared to specimens containing $2 \%$ and $4 \%$ filler content.

Stress at break, work at break and stress at maximum load all decreases linearly with increase in filler content.

All these may due to the following observation:

- Because of decrease in fluidity while fabricating.

- Fillers might not be evenly distributed.

- Adhesivity is decreasing.

\section{References}

[1] Pothan, L. A., Mai, Y. W., Thomas, S., and Li, R. K. Y. "Tensile and Flexural Behavior of Sisal Fabric/Poltester Textile Composites Prepared by Resin Transfer Moulding Technique".

[2] Suresha, B., and Siddaramaiah. 2007. "Mechanical and Tribological Properties of Glass-Epoxy Composites with and without Graphite Particulate Filler.” Journal of Applied Polymer Science 103 (4): 2472-2480.

[3] Deepak, M. V. S., and Subbaiah, K.M. 2008. “Three Body Abrasive Wear Behavior of Molybdenum-disulphide Filled Fiber Glass Epoxy Composite.” MACRO.

[4] Schutte, C. L. 1994. "Environmental Durability of Glass-Fiber Composites.” Mater. Sci. Eng. R 13 (7): 265-318.

[5] Daniel, I. M., and Yasmin, A. 2006, "Mechanical and Thermal Properties of Graphite Platelet/Epoxy Composites.” Composites Science and Technology 66 (9): 1182.

[6] Chand, N., and Jain, D. 2005. "Effect of Sisal Fiber Orientation on Electrical Properties of Sisal Fiber Reinforced Epoxy Composites.” Composites Part A 36: 594.

[7] Allitt, M. L., Whittaker, A. J., Onn, D. G., and Ewsuk, K. G. 1989. "A Study of the Thermal Conductivity of Alumina/glass Dispersed Composites.” International Journal of Thermophysics 10 (5): 1053-1062. 